\title{
Truthmaking in a realist fashion
}

\author{
Mengyu $\mathrm{Hu}^{1}$ iD
}

Received: 29 October 2021 / Accepted: 22 January 2022 / Published online: 9 February 2022

(C) The Author(s), under exclusive licence to Springer Nature B.V. 2022

\begin{abstract}
A large part of Asay's book, A Theory of Truthmaking, is dedicated to show the benefit of applying the truthmaking method to various debates in philosophy. In this paper, I will focus on Asay's discussion of realism in chapter 8, where he aims to define "realism" in terms of truthmaking and proposed three conditions to satisfy for an account to be realist. The third condition, "to maintain that those truths are true in virtue of that ontology in a relevant fashion", is mainly invoked to properly characterise quasirealism as anti-realist. This condition itself is intriguing but hard to understand. I will look into Asay's articulation on this condition and demonstrate the difficulties in interpreting it in a way that is consistent with Asay's methodological commitments. I will explore three interpretations of condition (iii): the second-order truthmaking interpretation (SOTI), the epistemic interpretation (EI), and the functional interpretation (FI). I will show that SOTI poses a dilemma to Asay's ontology-first truthmaking project, EI is undesirable because it deviates from the focus of ontology, and FI would render Asay's truthmaking account redundant.
\end{abstract}

Keywords Truthmaking $\cdot$ Realism $\cdot$ Quasirealism $\cdot$ Metaethics

In A Theory of Truthmaking, Asay discusses realism in the context of metaethics. Asay proposes to define realism in terms of truthmaking:

To be a realist with respect to a set of claims is (i) to be committed to the truth of some particular claims from the set, (ii) to be committed to an ontology of the relevant kind in virtue of which those truths are true, and (iii) to maintain that those truths are true in virtue of that ontology in a relevant fashion (Asay, 2020, p. 159).

Accordingly, a theory will be anti-realist if one or more of these three conditions is violated. Asay claims that his three-clause account does well in capturing what is going on within the metaethical realism debate. Here are some examples

Mengyu Hu

mengyu.hu@uconn.edu

1 Department of Philosophy, University of Connecticut, Storrs, CT, USA 
of anti-realist metaethical theories ruled out by each of the three conditions (see $\mathrm{p}$. 159, pp. 166-168): (i) rules out non-cognitivists, traditional emotivism (e.g. Ayer); (ii) rules out idealism, subjectivism, and constructivism; (iii) quasi-realism. Asay has argued that his account, if successful, has various benefits (for instance, solving Dreier's (2004) creeping minimalism problem). However, condition (iii), the claim that a realist theory has to "maintain that those truths are true in virtue of that ontology in a relevant fashion", is not sufficiently clear.

My goal is to critically examine how exactly this condition (iii) should be understood. Since contrasting quasirealism and realism is the only occasion where condition (iii) is appealed to, my interpretative task here is to understand what Asay's truthmaking account takes the key difference between quasirealism and realism to be.

\section{Quasirealism and Asay's condition (iii)}

Two features of Blackburn's quasirealism will be relevant to our later discussion. First, quasirealism is based on projectivism. Human beings have conative, actionmotivating mental states, such as emotions and preferences. We then "project" such inner states onto the external world, giving expression to these states in a propertyascribing way. For instance, one can express one's commitment to the obligation to alleviate suffering by uttering "Torture is wrong", where the property ascription "is wrong" does not pick out any worldly entity. Second, quasirealism respects the phenomenology of moral objectivity: even if we acknowledge the human-dependent origin of moral practices, such acknowledgement would not weaken our commitments to moral obligations. Quasirealists are willing to assert counterfactuals like the following:

[Quasirealist Counterfactual] "even if we had approved of it or enjoyed it or desired to do it, bear-baiting would still have been wrong... it is not our enjoyments or approvals to which you should look in discovering whether bear-baiting is wrong (it is at least mainly the effect on the bear)." (Blackburn, 1993, p. 153)

That is to say, regardless of how we feel, the wrongness of bearbaiting is always tied to the bad effects and pain inflicted on the bear.

Where does quasirealism stand with regard to Asay's account of realism? It is essentially an anti-realist theory, yet it maintains a strong hold on realist notions: on the one hand, the projectivist elements of quasirealism let us "gild and stain" the world with moral properties, making the theory anti-realist; on the other hand, as is demonstrated in [Quasirealist Counterfactual], quasirealism resembles realism in its insistence on moral objectivity. Asay explains the dual character of quasirealism with the following example. Consider the moral truth $<$ Kicking dogs is wrong $>$. Suppose naturalist realists take an object, $a$, to be the truthmaker. The object $a$ is a perfectly naturalistic entity: the existence of $a$ causes pain in dogs, which is enough to necessitate $<$ Kicking dogs is wrong $>$ (Asay, 2020, 162). The object $a$ is a 
pain-producer, which, strictly speaking, is different from pain. However, to simplify the discussion, Asay sometimes uses $a$ and pain interchangeably.

This example shows that, if focusing solely on the truthmaker cited by a quasirealist for moral truths, we would not hesitate to label this theory as realist. How could it still be anti-realist? This is where Asay's condition (iii) comes into play. Condition (iii) states that a realist theory has "to maintain that those truths are true in virtue of that ontology in a relevant fashion”. What makes Blackburn's theory anti-realist is therefore that he maintains moral truths are true in virtue of a naturalist realist ontology in an anti-realist fashion.

The contrast between a realist fashion and an anti-realist fashion of truthmaking is never explicitly stated. Instead, Asay articulates this contrast, in five different places, by explaining what distinguishes quasirealism from realism. The ways in which the realist/quasirealist contrast is formulated are quite diverse. The relevant passages share a common feature: what makes Blackburn's theory different from realism is his account of the relation between a moral truth and its truthmaker. Other than this point, these paragraphs seem to be discussing quite different questions.

Table 1 is a summary of the questions under discussion in each of the five paragraphs, with the respective answers from realists and quasirealists:

Each pair of answers is an attempt to cash out the contrast of "fashions" as required by the condition (iii). However, it is still hard to pin down the core requirement of condition (iii) because, strictly speaking, these questions are about quite different things. Take the questions raised by [A] and [D] for example. Asking "how $\mathrm{x}$ gets to be $\mathrm{y}$ " invites quite different answers from asking "how the fact that $\mathrm{x}$ is $\mathrm{y}$ uncovered to us" (compare this pair of question, for instance, with "how Tokyo gets to be the host for the 2020 Olympic Game" and "how the fact that Tokyo is the host is uncovered to us"). [A] and [E] also concern different subjects: [E] is reflecting on the kind of activity we engage in when we ask questions like the one in [A]. It is therefore hard to pin down what condition (iii) is asking for.

This lack of clarity of condition (iii) puts pressure on Asay's account of realism. In the following sections, I consider 3 interpretations of condition (iii).

One apparent constraint on the interpretation is that the reading should be consistent with the theoretical commitments of both Blackburn's quasirealism and Asay's truthmaking theory. Another constraint is that quasirealism and realism do not disagree over what truthmakers should be cited for a moral truth. This is important because the "gild and stain" metaphor makes it sound like that quasirealist's truthmaker is not pain per se, but pain gilded by our sentiments. But this is to take quasirealism as a form of error theory, which quasirealists like Blackburn explicitly deny.

\section{The second-order truthmaking interpretation (SOTI)}

This interpretation of condition (iii) is motivated by the paragraphs [A] and [B]. Recall the questions raised in these two paragraphs: "How does pain get to be a truthmaker for $<$ Kicking dogs is wrong $>$ ?", and "What makes it the case that pain 


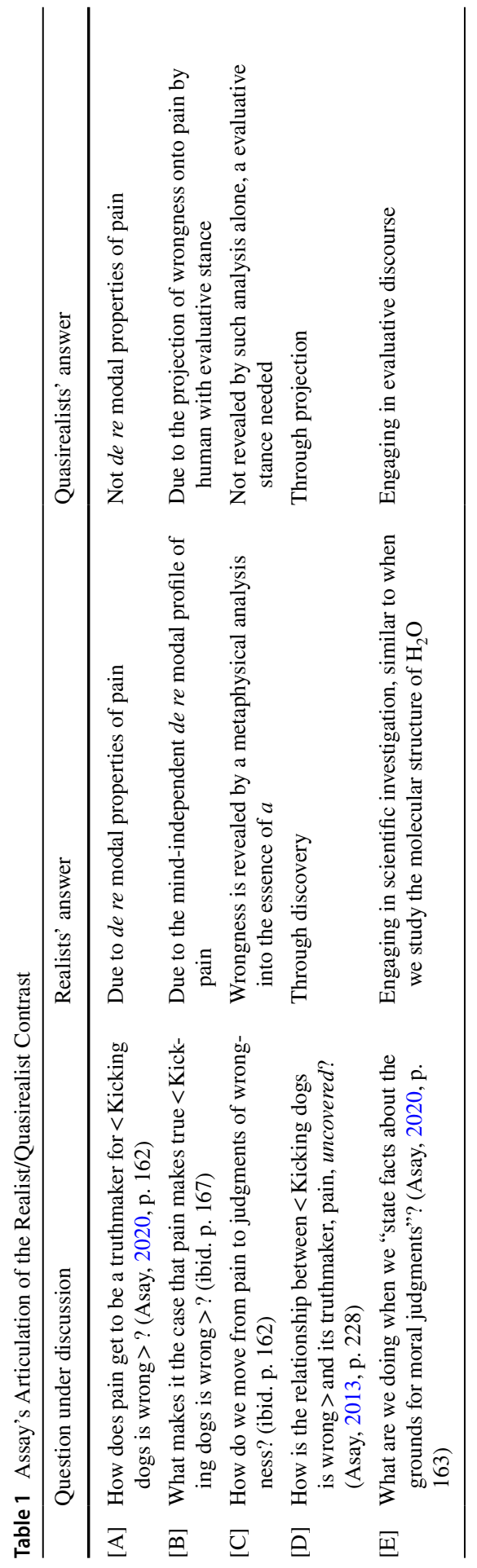


makes true $<$ Kicking dogs is wrong $>$ ?". Whatever object is cited to answer these questions could be seen as a truthmaker for a truth about truthmaking (Table 2):

Call this interpretation of condition (iii) the "second-order truthmaking interpretation" (SOTI):

$<$ Kicking dogs is wrong $>$ is true in virtue of the existence of pain in a realist-relevant fashion iff the second-order truthmaker for the truthmaking claim $<$ pain makes true $<$ Kicking dogs is wrong $>>$ commits the theory to an ontology of realist flavor.

The phrase "commits to an ontology of realist flavor" just means whatever is required by condition (ii).

SOTI is a natural way of understanding questions in [A] and [B]. Moreover, condition (iii) under this interpretation asks a question about truthmaking: this makes sure that the discussion of realism still falls squarely within the project of truthmaking.

However, SOTI is not compatible with Asay's own account, according to which a truthmaking project should take an ontological-first approach, and that a truthmaking relation is one of necessitation. If SOTI is correct, then the essential question over which realists and quasirealist disagree should be:

[Central SOTI Disagreement] What makes it the case that pain and $<$ Kicking dogs is wrong $>$ stand in a truthmaking relation.

This, as we learned from chapter 2 of Asay's book, has two plausible readings: one of the ontology-first approach, the other the explanation-first approach. According to the ontology-first approach, the question becomes:

[Central Ontological SOTI Disagreement] What has to exist in order for the first-order truthmaking relation to hold.

Under this reading, what distinguishes quasirealists from others is the view that the right kind of sentiment projection has to exist for pain to make true $<$ Kicking dogs is wrong $>$. Without such projections, it would be possible that kicking dogs is not wrong despite the pain it causes. This in effect shows that pain (or object $a$, in Asay's example) alone fails to necessitate the truth of the moral proposition, and thus fails to be its truthmaker. This conclusion contradicts what quasirealists believe (see the end of Sect. 1 for an explanation).

This contradiction dissolves only when ${ }^{1}$ we take the explanation-first reading of [Central SOTI Disagreement]. Under this alternative reading, the disagreement becomes:

[Central Explanatory SOTI Disagreement] Why does the first-order truthmaking relation hold?

\footnotetext{
1 Strictly speaking, two of Asay's commitments combined led to the undesirable result: ontology-first approach and truthmaking as necessitation. However, to give up necessitation means that even stronger requirements would be imposed on truthmaking relations, and that it would be even harder for pain to qualify as a truthmaker.
} 


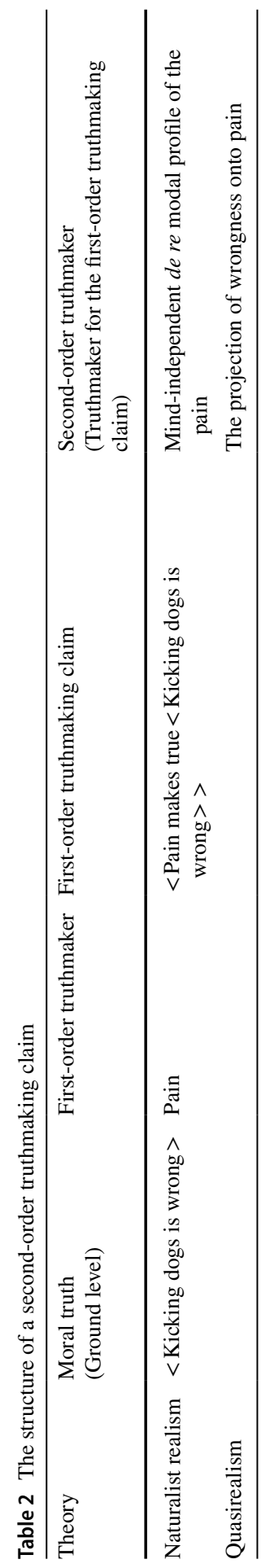


Then, quasirealists are distinguished by the view that the right kind of sentiment projection explains why pain makes true $<$ Kicking dogs is wrong $>$. The explanation here does not have to be an ontological one. Therefore, under this explanationfirst reading, quasirealists do not require the projection to exist for the truthmaking relation to hold.

This only solution presents a problem for SOTI: the only way to charitably capture quasirealism requires us to take truthmaking in an explanation-first approach, which Asay argues against extensively throughout the book.

\section{The epistemic interpretation (EI)}

The second interpretation is inspired by paragraphs [C] and [D], which poses the question "How do we move from pain to judgments of wrongness?" and "How is the relationship between $<$ Kicking dogs is wrong $>$ and its truthmaker, pain, uncovered?" respectively.

The question in [C] containing the "move from" locution asks about an epistemic transition: how do we move from the pain premise to the wrongness conclusion? And if the transition is justified at all, what establishes this epistemic connection between the two kinds of facts? Furthermore, the question in [D] asks how the truthmaking relation can be revealed to us. This is an inquiry into our epistemic access: both realists and quasirealists agree that this truth is true because of the object $a$, though realists think we get to know about this relation between the truth and the object $a$ by analyzing the nature of $a$, and quasirealists think we need to combine the study of $a$ and an evaluative stance in order to know. We might call this the epistemic interpretation (EI) of Asay's condition (iii):

$<$ Kicking dogs is wrong $>$ is true in virtue of the existence of pain in a realistrelevant fashion iff in order to know the truthmaking relation between $a$ and $<$ Kicking dogs is wrong $>$ we don't need to bring an evaluative stance into our analysis

We can understand this interpretation through an analogy of Frank Jackson's (1982) knowledge argument. If Mary has learned every physical fact about colors but lacks the conscious experience of the color red, then, as some will argue, she does not really know what redness is. Similarly, if someone has learned every physical facts about pain but never engaged in an evaluative stance, then he/she does not really know the truthmaking relation between pain and $<$ Kicking dogs is wrong $>$.

EI is not formulated in terms of truthmaking relations; and thus, we do not run the risk of giving up Asay's theoretical commitment to the ontology-first approach to truthmaking (as is questioned in Sect. 2).

I can see that there are strong reasons not to take this interpretation. EI is nonmetaphysical, which deviates from Asay's original intention to keep the realism debate entirely metaphysical. This intention marks an important methodological point because it captures the truism that realism is a commitment to what there is in the world and what the world is really like. 
Are there ways to make the epistemic interpretation a "fully metaphysical" interpretation? Maybe. One could argue that the difference with regard to our epistemic access only emerges due to some underlying metaphysical differences, and the epistemic talk is merely heuristic. Such tactics of converting seemingly epistemic talk into revelations of deeper metaphysical nature is not uncommon - for instance, the primary/secondary quality distinction can be put in epistemic terms. Is a similar metaphysical understanding of this epistemic interpretation of condition (iii) available? If Asay was to seriously consider the epistemic interpretation, maybe more light could be shed on how such an account can be constructed.

\section{The functional interpretation (FI)}

The third interpretation is motivated by the question discussed in [E]. Here, Asay spells out the difference in terms of the function of ontological talk. For realists, claims about the ontology for moral truths (i.e. "to say that pain grounds moral facts") and claims about the ontology for physical truths (i.e. "to say that $\mathrm{H} 2 \mathrm{O}$ grounds facts about water") are identical in kind, whereas for quasirealists, these two kinds of claims are very different: stating the first kind of claim is performing the function of engaging in evaluative discourse while stating the second kind does not fulfill the evaluative function. Let us call this the functional interpretation (FI) of Asay's condition (iii):

$<$ Kicking dogs is wrong $>$ is true in virtue of the existence of pain in a realistrelevant fashion iff the ontological talk about moral claims plays the same role as physical discourses and do not perform evaluative functions.

FI, like the epistemic interpretation, is a non-truthmaking account; and thus, it can avoid the difficulties faced by SOTI. But unlike the epistemic interpretation, FI would not be bothered by the quest to reveal the deeper metaphysical nature underlying the mere heuristic talk. According to FI, it is not the case that the difference in discourse functions reflects some deeper metaphysical structure, but instead, the talk of difference in metaphysical structures reflects the functional difference among discourses. This has in fact been a recurring theme in Blackburn's writing on quasirealism and projectivism. ${ }^{2}$ Throughout these various essays, Blackburn stresses this point: discourses of moral ontology do not perform the fact-representing function

\footnotetext{
${ }^{2}$ See, for instance, in Blackburn (1993), Morals and modals (p. 55), Errors and the Phenomenology of Value (p. 153), How to be an Ethical Anti-Realist (pp. 172 173).
} 
that its propositional form might suggest. ${ }^{3}$ It could be argued that, of all the interpretations of condition (iii), FI might be the one that best captures Blackburn's theory.

However, FI also comes with a cost for Asay: it makes Asay's truthmaking account redundant. If the difference between quasirealism and realism comes down to the fact that they think ontological talk of morality performs different functions, then the truthmaking or ontological accounting does not take on any explanatory duty. ${ }^{4}$ If the difference between quasirealism and realism comes down to the fact that they think ontological talk of morality performs different functions, why take the detour through truthmaking? Would it not be more straightforward to say that the two theories take moral discourses to perform different functions?

\section{Conclusion}

The central question of this paper is how condition (iii) of Asay's proposed account of realism should be understood. Given that the contrast between quasirealism and naturalist realism is the only place where condition (iii) is applied, I examined the passages where Asay describes this contrast. Based on these texts, three possible interpretations were discussed: the second-order truthmaking interpretation, the epistemic interpretation, and the functional interpretation.

I suggest that the functional reading is better than the others, as it avoids the difficulties faced by the second-order and epistemic readings, and best fits the spirit of Blackburn's projectivism. However, opting for the functional interpretation of condition (iii) makes the appeal to truthmaking unnecessary. Given that it was advertised as a strong advantage of truthmaking theory to properly characterize quasirealism, it is quite undermining if truthmaking is not doing the real work.

Funding The author is employed by the University of Connecticut and the research leading to this paper received funding from the University of Connecticut.

\footnotetext{
${ }^{3}$ Blackburn points out that there are two readings of the dependence questions like "what does the wrongness of cruelty depend on?": an internal reading that amounts to an offensive ethical view, a commitment, according to which the wrongness depends on the natural features of this action (i.e. causing pain); and an external reading, which only makes sense "if realism were true" and "treat the moral fact as a natural one, capable of being made or unmade by sensitivity" (Blackburn, 1993, p. 173). Quasirealists take such ontological talk of dependence as "moral talk or nothing" (ibid.). According to them, "[a] $\mathrm{s}$ soon as one uses a sentence whose simple assertion expresses an attitude, one is in the business of discussing or voicing ethical opinion. Such sentences include... 'our refined consensus makes it true that cruelty is wrong' and so on." (ibid. p. 174).

${ }^{4}$ In fact, we can have an account to distinguish quasirealists from other metaethical positions that are completely couched in functional terms, without any appeal to truthmaking talks at all. The key disagreement lies in their respective understanding of discourses on moral ontology: emotivists take such discourses to be nonsense (after all, what does it mean to ask for the ontological ground for "ouch"?); subjectivist, idealists, and constructivists all agree with realists in assuming that ontological talks serve to represent states of affairs; quasirealism is the only theory that takes the function of such talks not as representing but as "discussing and voicing attitudes" (Blackburn, 1993, p. 174)— in other words, for quasirealists, moral ontological talks of dependence like "the wrongness of kicking dogs depends on our refined attitudes" is functionally equivalent to the first-order moral claims like "kicking dogs is wrong".
} 


\section{References}

Asay, J. (2013). Truthmaking, metaethics, and creeping minimalism. Philosophical Studies, 163(1), 213-232.

Asay, J. (2020). A theory of truthmaking: Metaphysics, ontology, and reality. Cambridge University Press.

Blackburn, S. (1993). Essays in quasi-realism. Oxford University Press.

Dreier, J. (2004). Meta-ethics and the problem of creeping minimalism. Philosophical Perspectives, 18(1), 23-44.

Jackson, F. (1982). Epiphenomenal qualia. Philosophical Quarterly, 32, 127-136. 